\title{
Bone Cancer pTO TNM Finding v7
}

National Cancer Institute

\section{Source}

National Cancer Institute. Bone Cancer pTO TNM Finding v7. NCI Thesaurus. Code C88426.

Bone cancer with no evidence of primary tumor. (from AJCC 7th Ed.) 